NASA Technical Memorandum 102298

AIAA-89-2298

\title{
NASA's Chemical Transfer Propulsion Program for Pathfinder
}

Ned P. Hannum and Frank D. Berkopec

NASA Lewis Research Center

Cleveland, Ohio

Robert L. Zurawski

NASA Headquarters

Washington, D.C.

Prepared for the

25th Joint Propulsion Conference

cosponsored by the AIAA, ASME, SAE, and ASEE

Monterey, California, July 10-12, 1989 


\author{
NASA's Chemical Transfer Propulsion Program for Pathfinder \\ Ned P. Hannum and Frank D. Berkopec \\ NASA Lewis Research Center \\ Cleveland, Ohio 44135 \\ Robert L. Zurawski \\ NASA Headquarters \\ Washington, D.C. 20546
}

\begin{abstract}
Pathfinder is a research and technology project, with specific deliverables, initiated by the National Aeronautics and Space Administration (NASA) which will strengthen the technology base of the United States civil space program in preparation for future space exploration missions.

Pathfinder begins in Fiscal Year 1989, and is to advance a collection of critical technologies for these missions and ensure technology readiness for future national decisions regarding exploration of the solar system.

The four major thrusts of Pathfinder are: Surface Exploration, In-Space Operations, Humans-in-Space, and Space Transfer. The Space Transfer thrust will provide the critical technologies needed for transportation to, and return from, the Moon, Mars, and other planets in the Solar System, as well as for reliable and cost-effective Earth-orbit operations. A key element of this thrust is the Chemical Transfer Propulsion program which will provide the propulsion technology for high performance, liquid oxygen/liquid hydrogen expander cycle engines which may be operated and maintained in space. These advanced engines will enhance or enable a variety of future space exploration missions.

This paper describes the program overview including the goals and objectives, management, technical plan, and technology transfer for the Chemical Transfer Propulsion element of Pathfinder.

\section{INTROOUCTION}

\section{PROJECT PATHFINDER OVERVIEW}

American leadership on the space frontier requires aggressive programs in technology development. Technological advance will be critical to programs for future space exploration missions (Ref. 1). These missions may include an intensive study of the Earth, a return to the Moon, piloted missions to Mars, and the continuing robotic exploration of the Solar System (Ref. 2). The technologies needed for success in these ventures are many and varied. The National Aeronautics and Space Administration (NASA), recognizing that it must intensify and broaden the scope of its research and technology program to provide the range of technical options and evaluate technological readiness in select areas to enable future space exploration missions, is initiating Project Pathfinder.
\end{abstract}


Project Pathfinder is a research and technology initiative which will strengthen the technology base of the United States civil space program in preparation for future space exploration missions. Pathfinder is a long-term program of both research and demonstrations which begins in Fiscal Year 1989. It is managed by the NASA Office of Aeronautics and Space Technology (OAST) and has the goals to advance a collection of critical technologies for future space missions and to ensure technology readiness for future national decisions regarding exploration of the Solar System (Ref. 3).

Pathfinder is organized into four programmatic thrusts: 1) Surface Exploration, 2) In-Space Operations, 3) Humans-in-Space, and 4) Space Transfer, as shown in Figure 1. The Surface Exploration thrust will provide the critical technologies needed for gathering scientific and engineering data for robotic and piloted missions to the Moon, Mars and other planets in the Solar System. Technologies needed for Earth-orbit staging and operations, as well as planetary operations, will be provided in the In-Space Operations thrust. The Humans-in-Space Thrust will provide technology and understanding needed to ensure safe and productive human space exploration missions. Finally, the Space Transfer thrust will provide critical technology for transportation to, and return from, the Moon, Mars, and other planets in the Solar System, as well as for reliable and cost-effective Earth-orbit operations (Ref 4 ).

Chemical Transfer Propulsion is a key element of the Space Transfer thrust and will provide the technology for high-performance, liquid oxygen/liquid hydrogen expander cycle engines for space-based transfer vehicles, as well as for Lunar and Mars landers.

\section{CHEMICAL TRANSFER PROPULSION PROGRAM OVERVIEW}

\section{MISSION STUDIES AND TECHNOLOGY REQUIREMENTS}

In its report to NASA in 1987, the Committee on Advanced Space Technology of the National Research Council recommended that advanced propulsion technologies for future space missions be afforded the highest priority of R\&D activity within NASA. Recognizing that propulsion is a pacing item for future space exploration missions, the committee suggested that NASA pursue a strong program leading to the design and development of reusable cryogenic transfer vehicle engines with features of fault tolerance, high reliability and longevity (Ref. 5). The NASA Office of Aeronautics and Space Technology has responded with the Chemical Transfer Propulsion element of Pathfinder. which will provide the technology necessary to confidently proceed with the development of high performance liquid oxygen/liquid hydrogen expander cycle engines for future space exploration missions, as well as to fulfill the orbit transfer role in Earth space.

NASA's planning for future exploration of the solar system includes unmanned (precursor) and manned missions to Mars and its moons, as well as a resumption of manned missions to the Moon to establish Lunar observatories. A portion of the cost for these missions depends on launch vehicle and on-orbit fuel requirements. One of the keys to reducing cost is to minimize the propellant mass in low-Earth orbit required to achieve a transfer trajectory, to accomplish orbit insertion, to effect a planetary landing, and 
to return to Earth. Launch of the many millions of pounds required for virtually all future space exploration mission scenarios may be affordable only if advanced propulsion systems can be made available (Ref. 5). Reduced propellant requirements in orbit translate to substantial cost savings because fewer Earth-to-orbit vehicle launches are required to accomplish the mission. For example, in the case of a manned Mars mission, an increase of 35 seconds of engine specific impulse saves the cost of at least two Earth-to-orbit vehicle launches. A key enabling technology to greatly reduce in-orbit propellant mass requirements is the development of high-performance chemical transfer engines.

Another key to reduced cost is to develop reusable transfer stages that are based in and operated from low-Earth orbit, are operated in low-Earth orbit (LEO) to geosynchronous orbit (GEO) space, and are used in the exploration missions. Technologies that will enable automated in-orbit operation (such as refueling, maintenance, servicing, and preflight systems checkout, as well as fault-tolerant in-flight operation) are critical to the successful development and use of space-based vehicle systems. Integrated controls and health monitoring systems will be required for such fault tolerant engines which will be repeatedly operated and maintained in space.

The NASA Office of Exploration (OEXP) is currently studying several mission scenarios to provide recommendations and alternatives for an early 1990's national decision on a focused program for human exploration of the Solar System. These mission scenarios include human expeditions to the Martian moon Phobos, human expeditions to Mars, human tended Lunar observatories, and an evolutionary expansion from a Lunar outpost to Mars exploration (Ref. 6). A preliminary set of propulsion technology requirements generated by OEXP for these mission scenarios is presented in Table I. Requirements for these propulsion systems include: 1) fault tolerance and high reliability, 2) space basing, long life, and space maintainability, 3) man rating, 4) reusability, restart capability, and checkout before reuse, 5) diagnostic capability (integrated controls and health monitoring), and 6) some level of on-orbit assembly.

\section{TECHNOLOGY ASSESSMENT}

The only upper stage liquid oxygen/liquid hydrogen expander cycle engine currently in operation is the RL10 engine which was developed and certified in the late 1950's and early 1960's. Two RLIOA-3-3A engines are used on the expendable Atlas Centaur vehicle. The RLIOA-3-3A is a regeneratively cooled, turbopump-fed rocket engine that weighs approximately 310 pounds and produces a rated vacuum thrust of 16,500 pounds (Ref. 7 ). With a chamber pressure of 465 psia, the engine delivers moderate performance (444.4 seconds specific impulse at mixture ratio of $5: 1$ using a $61: 1$ area ratio nozzle), has limited throttling capability (with significant performance penalties) and no on-board diagnostics. It was designed for and is only used on expendable vehicles.

In the early 1970's. NASA initiated a technology program directed toward an advanced liquid oxygen/liquid hydrogen upper stage engine, as shown in Figure 2. The program initially focused on an advanced space engine utilizing a staged combustion cycle for very high pressure, high performance 
operation. The Advanced Space Engine technology program was carried through component verification testing, at which time it was decided that a liquid oxygen/liquid hydrogen expander cycle engine would better satisfy future mission requirements. The Orbital Transfer Rocket Engine technology program, which began in the early 1980's, focused on advanced component technologies for high performance (high pressure), reusable liquid oxygen/liquid hydrogen expander cycle engines which would be space based and man-rated. Efforts were focused on technologies for high-speed turbomachinery, hlgh-heat-transfer combustors, large-area-ratio nozzles, and health monitoring systems. The basic proof-of-concept of advanced, high-performance liquid oxygen/liquid hydrogen expander cycle components was only partially demonstrated during this program, which has given way to the chemical Transfer Propulsion Program. Some limited testing of turbomachinery and health monitoring components (sensors) in a breadboard engine was also conducted.

What remains to be accomplished in order to confidently proceed with the development of an advanced high performance liquid oxygen/liquid hydrogen expander cycle engine for future space exploration missions is: 1) the validation testing of engine components, 2) integration and testing of components assembled into an engine system (to study component interactions, system transients, system dynamics, and health monitoring/control systems). and 3 ) the verification of design and analysis methodologies at both the engine component and engine system leve1. Pathfinder Chemical Transfer Propulsion is a focused program intended to elevate technology readiness (to Level 6 as shown in Table II) by bridging the technology gap between basic research and technology efforts conducted to date (Level 3 ) and the eventual development of advanced liquid oxygen/liquid hydrogen engines for space transfer vehicles.

\section{CHEMICAL TRANSFER PROPULSION PROGRAM GOALS AND OBJECTIVES}

The goal of the Chemical Transfer Propulsion Program is to provide the technology necessary to confidently proceed, in the 1990's, with the development of high-performance, liquid oxygen/liquid hydrogen expander cycle engines for future space exploration missions. Major program objectives are:

(1) Proof-of-concept demonstration of a high performance, liquid oxygen/liquid hydrogen expander cycle in a test bed engine system, including:

(a) Validation of high pressure, high performance expander cycles

(b) Investigation of engine system interactions, transients, dynamics, control functions, and health monitoring techniques

(2) The validation of a design and analysis methodologies to support the development of future, high performance liquid oxygen/liquid hydrogen expander cycle engines including;

(a) Assembly and validation of analytical methodologies for the design of advanced liquid oxygen/liquid hydrogen expander cycle engine components and systems 
(b) Validation of design concepts for high performance, space-based, throttleable liquid oxygen/liquid hydrogen expander cycle engines

(3) Mission-focused components integrated into a focused-technology test bed engine to demonstrate the high performance, liquid oxygen/liquid hydrogen expander cycle engine system technology that is to be the basis for future space engine development

(4) Results of propulsion studies conducted to define firm propulsion requirements and to trade propulsion system performance, configuration, operating characteristics, and the attributes that are key to long-term space transportation infrastructures (space-basing. reuse, man-rating, fault tolerance)

\section{TECHNICAL APPROACH}

At the present time, future space exploration mission scenarios have not been defined to a point where firm propulsion requirements exist. However, technology goals for an advanced liquid oxygen/liquid hydrogen space engine which support the range of future mission options are presented in Table III. The major technical issues for an advanced liquid oxygen/liquid hydrogen expander cycle engine which will be addressed in the Chemical Transfer Propulsion Program are:

(1) High performance:

High performance engine operation (Goal of $4901 \mathrm{bf}-\mathrm{sec} / \mathrm{lbm}$ vacuum specific impulse)

(2) Deep throttling:

Continuous and stable engine operation from rated thrust to perhaps 5\% (20:1 vacuum thrust throttling ratio) with minimum performance loss

(3) Reusability:

Specifications of the number of starts and the number of hours of operational life, as well as the number of starts and hours of service-free life are to be established; preliminary assessments are: 500 starts/20 hours operational life, 100 starts/4 hours service free life

(4) Space Basing:

Modular engine design for space maintenance, operating characteristics and diagnostics and techniques that facilitate long-term storage and operations in space

(5) Fault tolerance:

Fault tolerance in the "classical" sense: the propulsion system shall tolerate a given number of failures without causing a hazard, 
or fail operational/fail safe (as an additional requirement, the system shall tolerate off-design operation of some combinations of components in a way that maintains system durability to allow completion of the mission)

(6) Man rating

High reliability; redundancy of all critical systems; design and operational safety; proven design standards; enable safe haven or return

The technical approach to be used in the Chemical Transfer Propulsion Program is summarized in Figure 3. The program consists of propulsion studies, focused advanced component technology efforts, and systems technology activities. Orawing on technology developed in the Orbital Transfer Rocket Engine Technology program, advanced liquid oxygen/liquid hydrogen expander cycle engine components will be designed, fabricated and tested in component test stands. The components will then be assembled into a test bed engine for systems testing. In parallel with these activities, propulsion studies will be conducted to define propulsion system requirements which will guide the selection of focused advanced component technologies to be pursued in the program. The focused advanced engine components emerging from these efforts will be integrated into a focused-technology test bed engine. This engine system will be tested to complete Level 6 of technology readiness.

\section{MANAGEMENT PLAN}

\section{OVERVIEW}

The Chemical Transfer Propulsion Program is a focused technology program leading to technology demonstrations of an advanced liquid oxygen/liquid hydrogen expander cycle engine system and engine components. The extensive variety of work being performed in the program requires a management approach which is tailored to coordinating and integrating the various work activities. The management system must ensure achievement of planned accomplishments, effective reporting and control, and permit prompt replanning if required. The work breakdown structure, management structure, program coordination, planning and documentation, reporting, and advisory groups for the Chemical Transfer Propulsion program are described in this section.

\section{WORK BREAKDOWN STRUCTURE}

The Chemical Transfer Propulsion program is divided into three major research areas which allows work to be focused in critical areas and provides a flow mechanism for raising the technology to higher levels of hardware definition, leading to the eventual testing of an advanced liquid oxygen/liquid hydrogen expander cycle focused-technology test bed engine in the late 1990's. The major work packages are; (1) Propulsion Studies (2) Mission-Focused Technologies and (3) Engine Systems Technologies. Figure 4 illustrates the top-level work breakdown structure elements. The work flows from one element to the succeeding one. The propulsion studies will generate propulsion requirements to guide the selection of mission-focused technologies. Advanced engine subcomponents and components emerging from the 
mission-focused technology efforts will be tested in an engine system in the focused-technology test bed.

\section{ORGANIZATION AND MANAGEMENT STRUCTURE}

Program management responsibilities for the Chemical Transfer Propulsion Program will reside in OAST's Propulsion, Power and Energy Division. A Program Manager will establish overall programmatic goals and objectives and serve as the focal point at NASA Headquarters for the Chemical Transfer Propulsion Program. The Chemical Transfer Propulsion Program Manager will report on regular basis to the Program Manager for Pathfinder as to the status, problems and accomplishments of the program.

The NASA Lewis Research Center (LeRC) will be the lead center for the Chemical Transfer Propulsion Program. As the lead center, LeRC will assume full responsibility of achieving the goals and objectives of the program, as well as for integrating next-tier assignments in the program both within LeRC and at participating Centers.

The Lewis Research Center will plan and integrate Chemical Transfer Propulsion activities and execute some portion of that plan within the Center. A Project Manager located at LeRC will be the focal point of all field installation activity bearing directly on the Chemical Transfer Propulsion Program and will be exclusively responsible for the execution of the program. In essence, the Project Manager will be responsible for the day-to-day supervision and the execution of the program as carried out by industrial contractors, field installation personnel, and university participants. These responsibilities include: 1) technical planning, 2) maintaining and reporting schedules, 3) planning, disbursement and tracking of resources, and 4) facility planning as required.

The Chemical Transfer Propulsion Management Structure is depicted in Figure 5 .

\section{PROGRAM COORDINATION}

The LeRC Project Manager will be kept informed and will coordinate information with the Office of Exploration (OEXP), and the office of Space Flight (OSF), to assure that future space vehicle requirements guide propulsion technology efforts within the Chemical Transfer Propulsion program. OEXP will define scenarios for future, human exploration missions in the Solar System. OSF will establish space vehicle requirements for these future space exploration missions, which will guide the development of propulsion technologies. Mission and vehicle definition will be important in determining propulsion system characteristics such as; (1) minimum performance requirements, (2) thrust level, (3) throttling requirements, (4) 1 ife, reliability and reusability requirements and (5) design criteria for in-space engine operation and maintenance.

Within OAST, coordination will be maintained with the propulsion R\&T Base program, as applicable to chemical transfer propulsion technologies. External to OAST, coordination will also be maintained with the Department of Defense through the Joint Army, Navy, NASA, Air Force (JANNAF) Interagency Propulsion 
Committee and the NASA/AF Space Technology Interdependency Group (STIG) for the exchange of information and technology where propulsion technologies and application are common.

\section{PROGRAM REVIEWS}

Formal reviews of the Chemical Transfer Propulsion Program will be conducted semi-annualiy; mid-way during, and near the end of, each fiscal year. The focus of the mid-fiscal year review will be on program content, status and progress versus the Project Plan. Test results, experimental and analytical data, and program accomplishments will be central to this review. The review will include an advisory committee for the Chemical Transfer Propulsion program and principal managers and technical specialists directly involved in the program from Headquarters (Program Manager), the lead center (Project Manager), participating centers, contractors and universities.

The purpose of the review near the end of the fiscal year will be to evaluate the specific Project Plan against schedule, accomplishments and resources. During this formal review, each participating center will represent its area of expertise and responsibility. The lead center will be responsible for making an integrated assessment of progress and accomplishments versus the Project Plan. Special, detailed technical reviews will also be conducted as necessary to ensure a planned pace of accomplishment to meet the goals and objectives of the program and to expose any problems or potential malfunctions before committing the program to the next step. These special reviews will include:

(1) Review of design and analys is methodologies for liquid oxygen/liquid hydrogen expander cycle engine components/systems

(2) Preliminary and critical design reviews for the test bed engine

(3) Propulsion system trade studies

(4) Technology reviews for advanced (mission-focused) engine components (prior to their integration into the focused-technology test bed)

(5) Engine systems technology review (prior to integration of the test bed engine system into the focused-technology test bed)

Additionally, there will be special technical reviews scheduled and implemented by the LeRC Project Manager.

\section{ADVISORY COMMITTEES}

The OAST Space Systems Technology Advisory Committee (SSTAC) and the Aerospace Research and Technology Subcommittee (ARTS) will be utilized for the Chemical Transfer Propulsion program. These advisory groups will provide top-level programmatic and technical guidance to the program. In addition, a Space Propulsion Advisory Committee will provide a more specific advisory function to the Chemical Transfer Propulsion Program. This committee composed 
of principal managers and technical specialists from NASA, other government agencies, industry and academe and will provide specific programmatic and technical guidance to the program once each year at the mid-fiscal year revtew.

\author{
TECHNICAL PLAN
}

\title{
TECHNICAL OVERVIEW
}

The Chemical Transfer Propulsion program will evolve fundamental liquid oxygen/liquid hydrogen expander cycle propulsion technologies through component, subsystem and system hardware demonstrations. Work in the Base R\&T program over the past several years has been directed towards establishing engine design concepts capable of meeting expected mission requirements and pursuing critical technology advances necessary to achieve performance, life, and operational goals. Advanced design concepts and analytical methods have also been developed using laboratory and specially designed test equipment.

The Chemical Transfer Propulsion program will build on the R\&T Base by moving progressively through full-scale component, subsystem, and system level validations and demonstrations. Propulsion studies, mission focused technology efforts, and engine system technology efforts will be conducted, leading to the testing of a high performance liquid oxygen/liquid hydrogen expander cycle engine with mission focus. The objectives and overall technical approach for each of these three elements are described in the following sections.

\section{TECHNOLOGY READINESS OBJECTIVES}

The technology readiness level of the liquid oxygen/liquid hydrogen expander cycle engine, as the Chemical Transfer Propulsion program is initiated in Fiscal Year 1989, can be considered Level 3, as shown in Table II. Key components and related component analytical models for high performance liquid oxygen/liquid hydrogen expander cycle engines, such as pumps, turbines, thrust chambers and health monitoring devices, have been designed, fabricated and tested for proof-of-concept in the Base R\&T program over the past several years. With this as a starting point, the Chemical Transfer Propulsion program will design, fabricate, and test components based on these proof-of-concept designs. These components will be tested in component test stands to determine expected performance and validate analysis and design methodologies.

When the technology readiness is be elevated to Leve 14 , the components will be integrated into a test bed engine for system characterization testing. Advanced engine components emerging from the Mission-Focused Technology element will be integrated with the test bed engine to form a focused-technology test bed and elevate technology readiness to Level 5 . System validation of hardware and analysis concepts will be conducted in the focused-technology test bed in a simulated space environment to complete Level 6 of technology readiness. At this point in the program, in the late 1990's, the goals and objectives of the Chemical Transfer Propulsion program will be met. Validated hardware and design methodologies will be available to the development program. 


\section{PROPULSION STUDIES}

objectives. Propulsion system studies will be conducted in the Chemical Transfer Propulsion Program to provide engine parametric data to support the mission/vehicle studies being conducted by the OEXP and the OSF. The studies will also identify and assess the technology requirements of candidate propulsion systems resulting from the vehicle studies.

Technical Approach. The initial propulsion system parametric data packages needed for the mission/vehicle studies will be generated as a task under the existing OTV (Orbit Transfer Vehicle) Rocket Engine Technology contracts with Aerojet TechSystems Company. Pratt \& Whitney, and Rocketdyne. These data packages will be provided to the OEXP and OSF vehicle contractors. Provisions will be made to enable close coordination between vehicle and engine study contractors such that the impact of vehicle derived requirements on the engine system can be assessed and the results utilized in the vehicle trade studies.

Once propulsion system requirements for the vehicles have been defined, mission-focused propulsion system studies will be conducted to optimize the engine components and/or systems. These studies will be used to guide the Mission-Focused Technologies activity.

Schedule of Milestones and Deliverables. The objectives for this element are to support the mission/vehicle studies by OEXP and OSF and to implement the results of the mission vehicle studies into the Chemical Transfer Propulsion Program.

Deliverables are:

(1) Engine parametric data packages

(2) Special engine parametric data packages

FY90

(3) Mission-focused engine component requirements

FY92

(4) Propulsion trade studies

FY92

\section{MISSION-FOCUSED TECHNOLOGIES}

Objective. The objective of Mission Focused Technologies is to provide mission-specific technology for inclusion into the Focused-Technology Test Bed engine that is scheduled for 1994. This technology will complement the results of the earlier engine technology from the OTV effort. The Mission-Focused Technologies will include those issues that have not yet been defined; but are size, mission, and cycle specific. These issues are not being covered in the early engine technology effort but will be defined as a result of ongoing propulsion studies.

Technical Approach. The technical approach will be to define those technology issues that are specific to a space-based, man-rated, reusable, fault-tolerant, liquid oxygen/liquid hydrogen expander-cycle engine that will be used for future space exploration. Definition will come from 
the propulsion studies. They will be the thrust level, throttleability range, mixture-ratio range, and size envelope. Where these aspects can not be defined, a broad range of values will be pursued. Up-dating of the configuration and cycle candidates will also be results of the propulsion studies. With this narrowing of configurations, the technology issues specific to these configurations will be identified.

Once identified, these technology issues will be pursued both as individual components, and as sub-systems in a series of proof-of-concept tasks (Level 3). These tasks would lead next to the component validation work at Level 4, and ultimately to the test bed engine demonstration work at Level 5 .

Schedule of Milestones and Deliverables. The key milestone for this work package is to provide demonstrated mission focused components for the build-up of the focused-technology test bed engine in FYg4. A supplementary milestone is to have all of the mission-focused components available and characterized by FY 97.

In order to meet these goals, several intermediate milestones can be listed. One is to have proof-of-concept validated mission-focused components (Level 3) completed in FY 92. To accomplish this, work on the mission-focused components must start in FY 89.

\section{ENGINE SYSTEMS TECHNOLOGY}

Objectives. The objectives of this work package element are: 1) validation of the high pressure, high performance expander cycle concept at the engine system level, 2) verification of the 1989 state-of-the-art methodologies for design and analys is of high pressure, high performance expander cycle components and engine system, 3) investigation of system effects on component design, control functions, and health monitoring techniques, and 4) demonstration of advanced, mission-focused components in a focused-technology test bed engine. The testing of the focused-technology test bed engine in a simulated environment will be the demonstration of the chemical transfer propulsion technology base for future space exploration missions.

Technical Approach. The Engine Systems Technology will consist of one or more contract efforts and an in-house NASA LeRC effort.

Using the technology developed in the R\&T Base in the 1980's, a contractor or contractors will design, fabricate, acceptance test, and deliver to NASA LeRC advanced, high pressure, high performance expander cycle test bed engines. Test bed engine design will utilize the state-of-the-art design and analysis methodologies available. These methodologies will be verified during contractor testing of engine components and during the NASA LeRC in-house test bed engine test program.

The NASA LeRC in-house effort will be an extensive test program of the test bed engine to: 
(1) Validate the high pressure, high performance expander cycle concept at the engine system level

(2) Investigate engine system interactions, transients, and dynamics and what effect they have on mission-focused component designs

(3) Investigate engine control functions and health monitoring techniques to help direct the mission-focused technology efforts

(4) Verify engine system design and analysis methodologies

As advanced components emerge from the Mission-Focused Technologies efforts they will be integrated into the test bed engine for system level testing. In this manner, the 1989-technology test bed engine will evolve into a focused-technology test bed engine in the 1994-1996 time period.

\section{TECHNOLOGY TRANSFER PLAN}

The effective transfer of propulsion technologies from the research center to the development center where the technology will eventually be developed into operational systems for future space transfer missions is recognized as a major goal of the Chemical Transfer Propulsion Program. Planning for the transition of Chemical Transfer Propulsion technology to advanced development in preparation for implementation involves both Headquarters and the field centers.

\section{REFERENCES}

1. Pioneering the Space Frontier. The Report of the National Commission on Space; Bantum Books, 1986.

2. Ride. S.K.: Leadership and America's Future in Space. NASA TM-89638, 1987.

3. Project Pathfinder: Technology Benefits Assessment. Office of Aeronautics and Space Technology, NASA, Nov. 1987.

4. Project Pathfinder: Research and Technology to Enable Future Space Missions. Office of Aeronautics and Space Technology, NASA, Brochure/JPL 400-330, Dec. 1987.

5. Space Technology to Meet Future Needs. National Research Council. National Academy Press. Washington, D.C. 1987. (NASA CR-181473.)

6. Prerequisite Requirements for Exploration Class Missions. Version 2.1. NASA Office of Exploration Document No. Z-MAS-PRD-003. May 1988.

7. RL-10 Liquid Rocket Engine Service Manual: Model RL10-10A-3-3A. United Technologies, Pratt \& Whitney Aircraft Group, Feb. 15, 1982. 


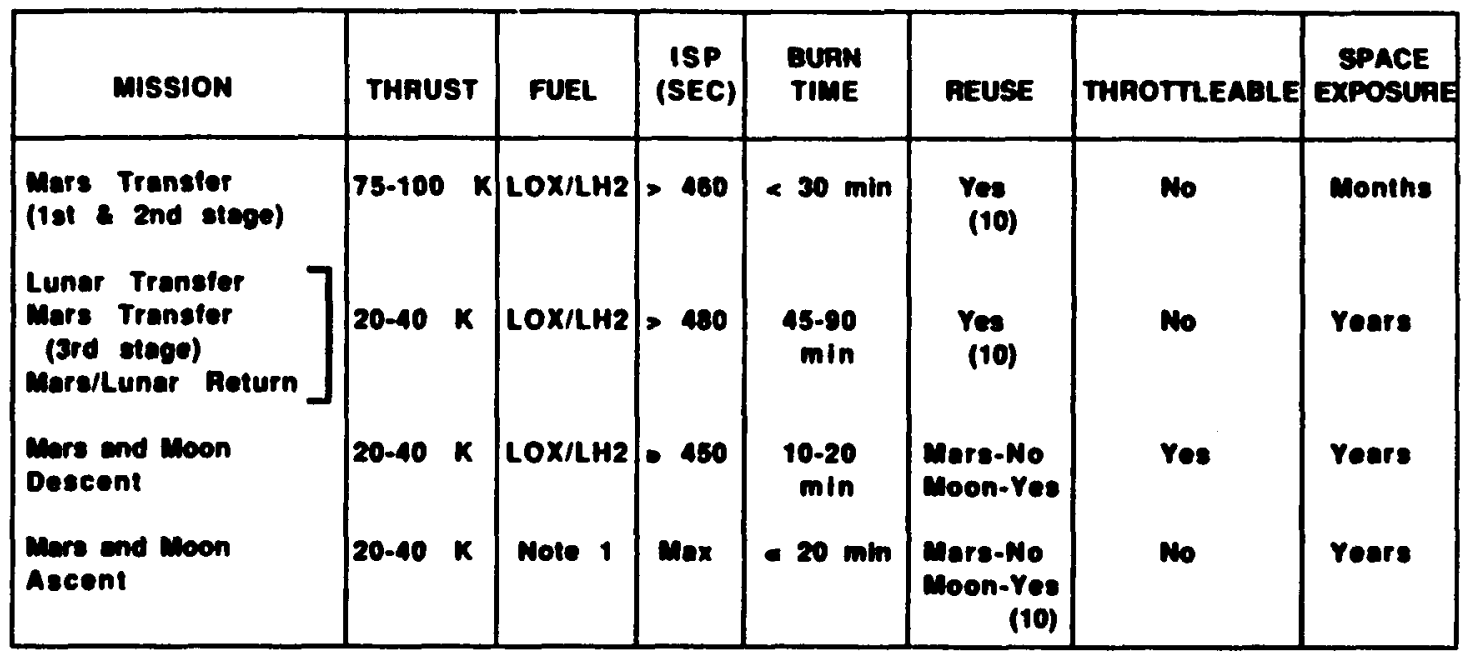

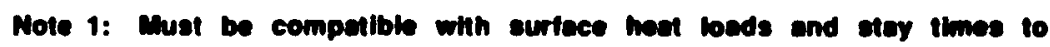
reduce propellant losses to mission sccepteble levels

Table I: Chemical Transfer Propulsion Technology Requirements

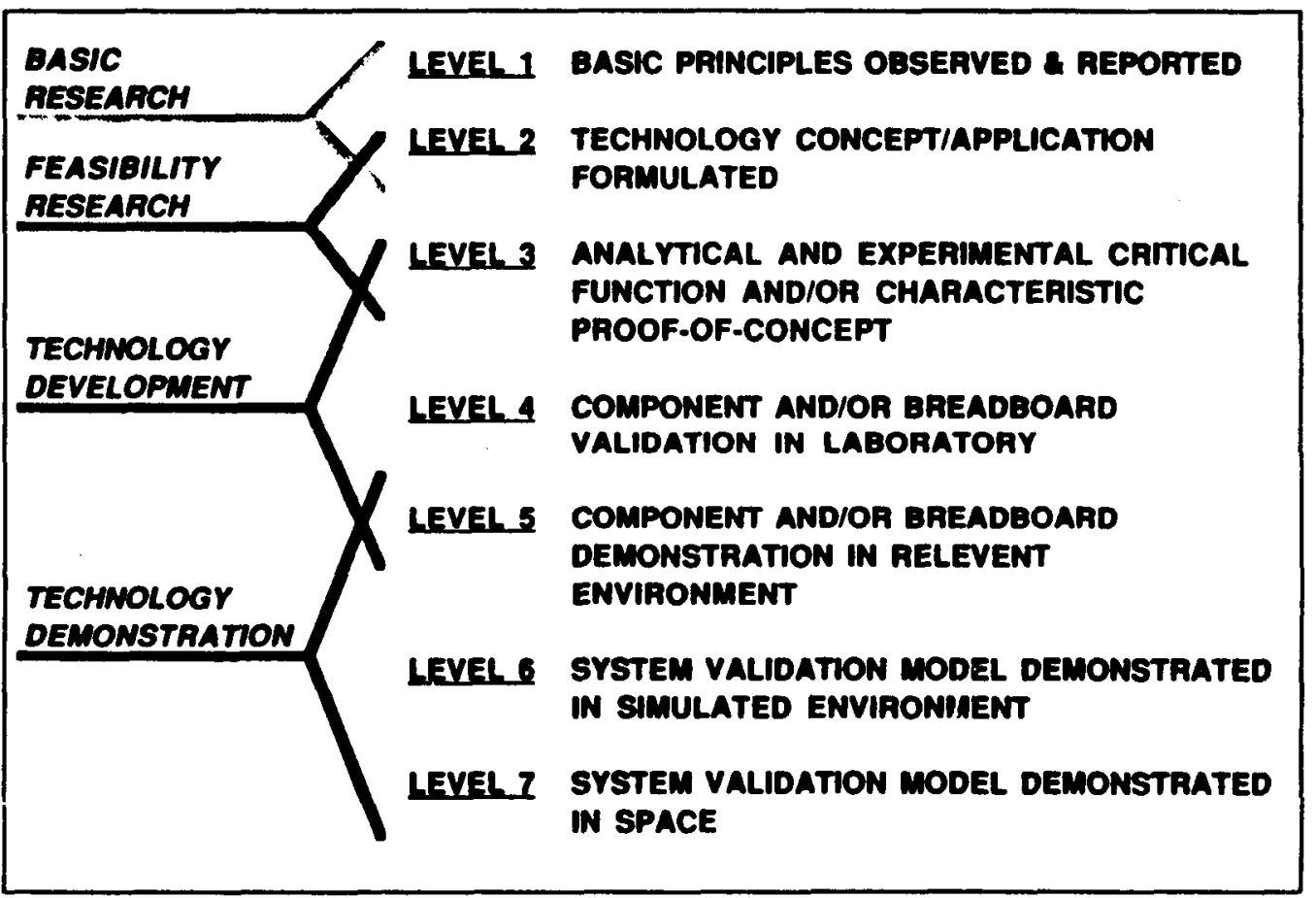

Table II: Technology Readiness Levels 


\begin{tabular}{|c|c|c|}
\hline Parameter & $\begin{array}{l}\text { Aoterence } \\
\text { Engine Syetem } \\
\text { (RL-10A-3-3A) }\end{array}$ & $\begin{array}{l}\text { Spese Tronster } \\
\text { Vemiel Engine } \\
\text { Technology Coele }\end{array}$ \\
\hline 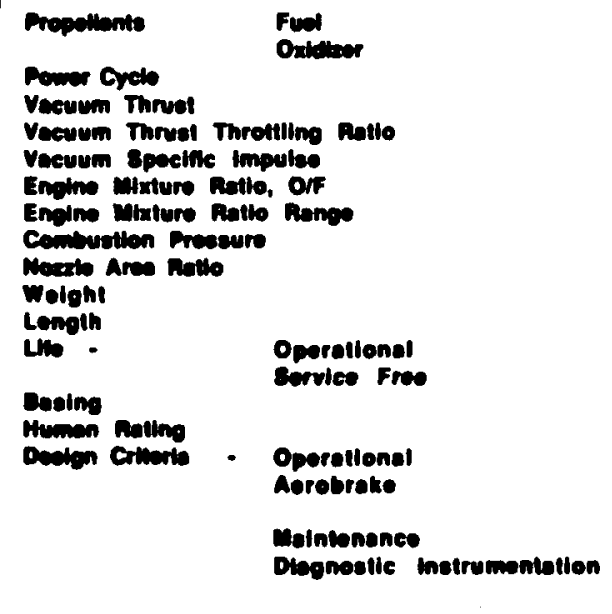 & 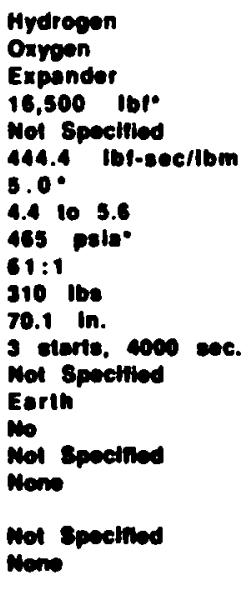 & 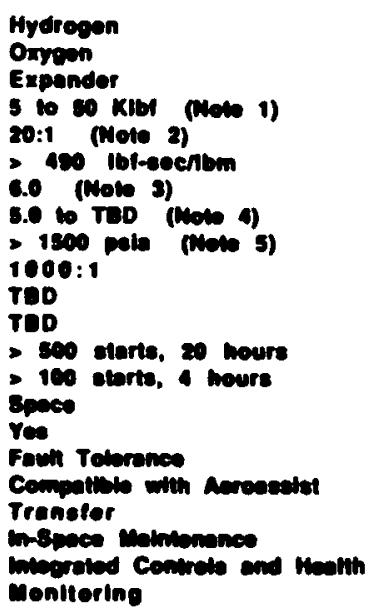 \\
\hline 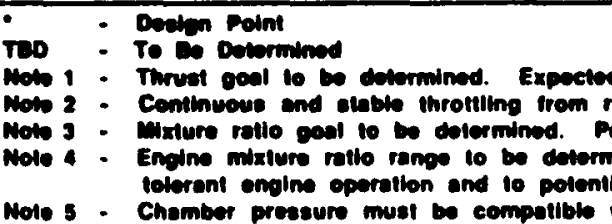 & 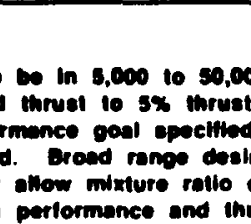 & 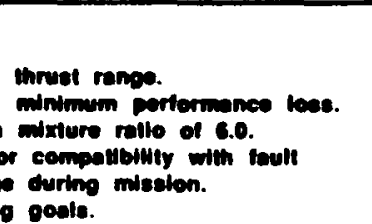 \\
\hline
\end{tabular}

Table III: Technology Goals for Space Transfer Engine

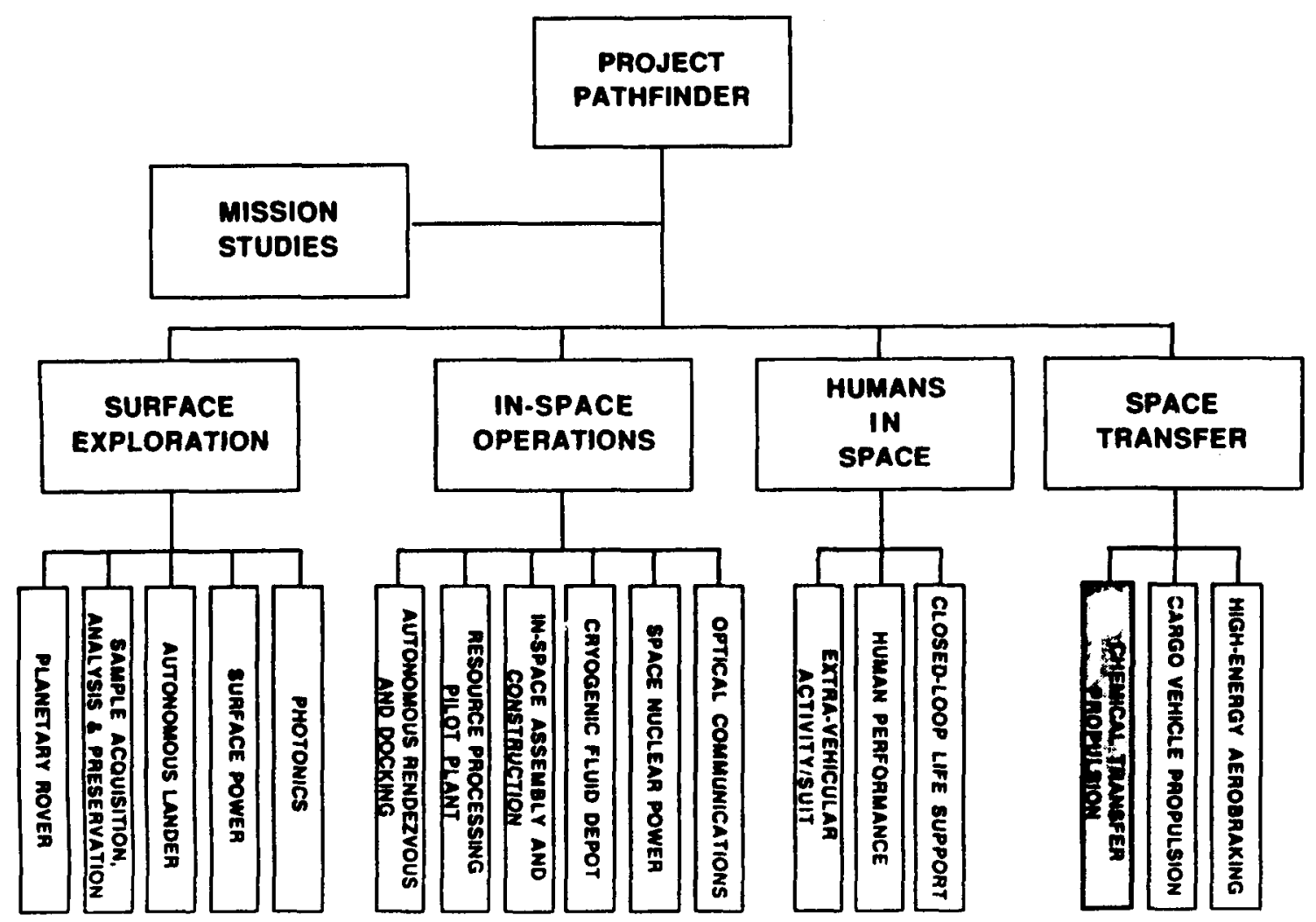

Figure 1: Project Pathfinder Work Breakdown Structure 


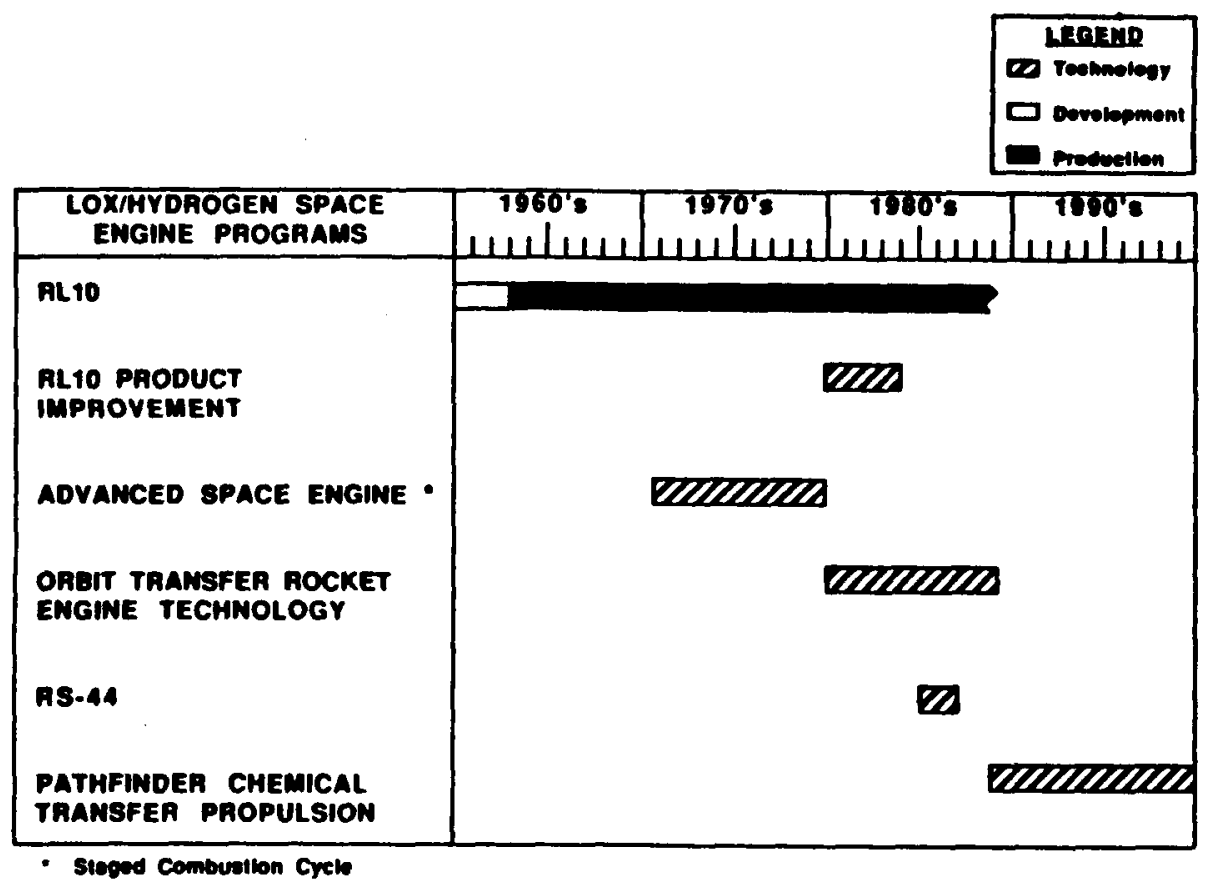

Flgure 2: Lox/Hydrogen Upper Stage Engine History

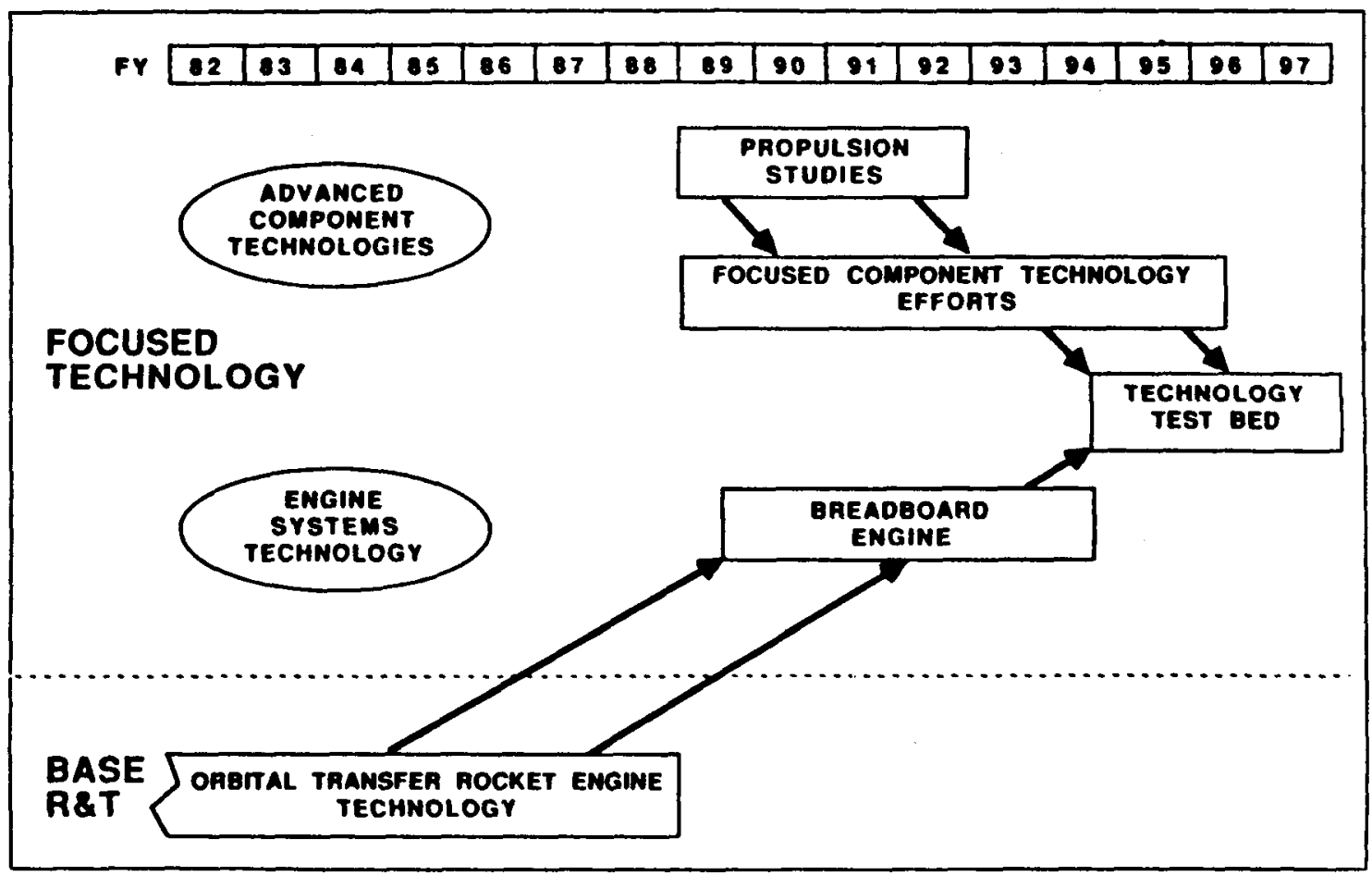

Figure 3: Chemical Transfer Propulsion Technical Approach 


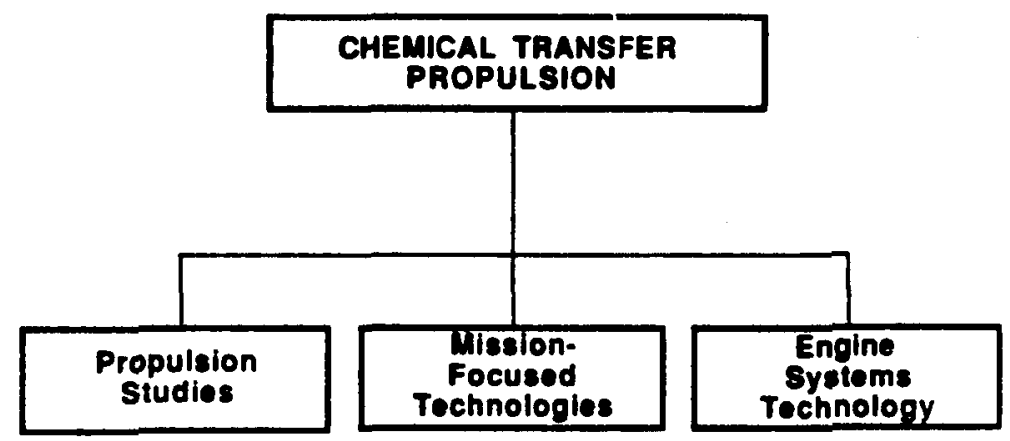

Figure 4: Work Breakdown Siructure for Chemical Transfor Propulsion Program

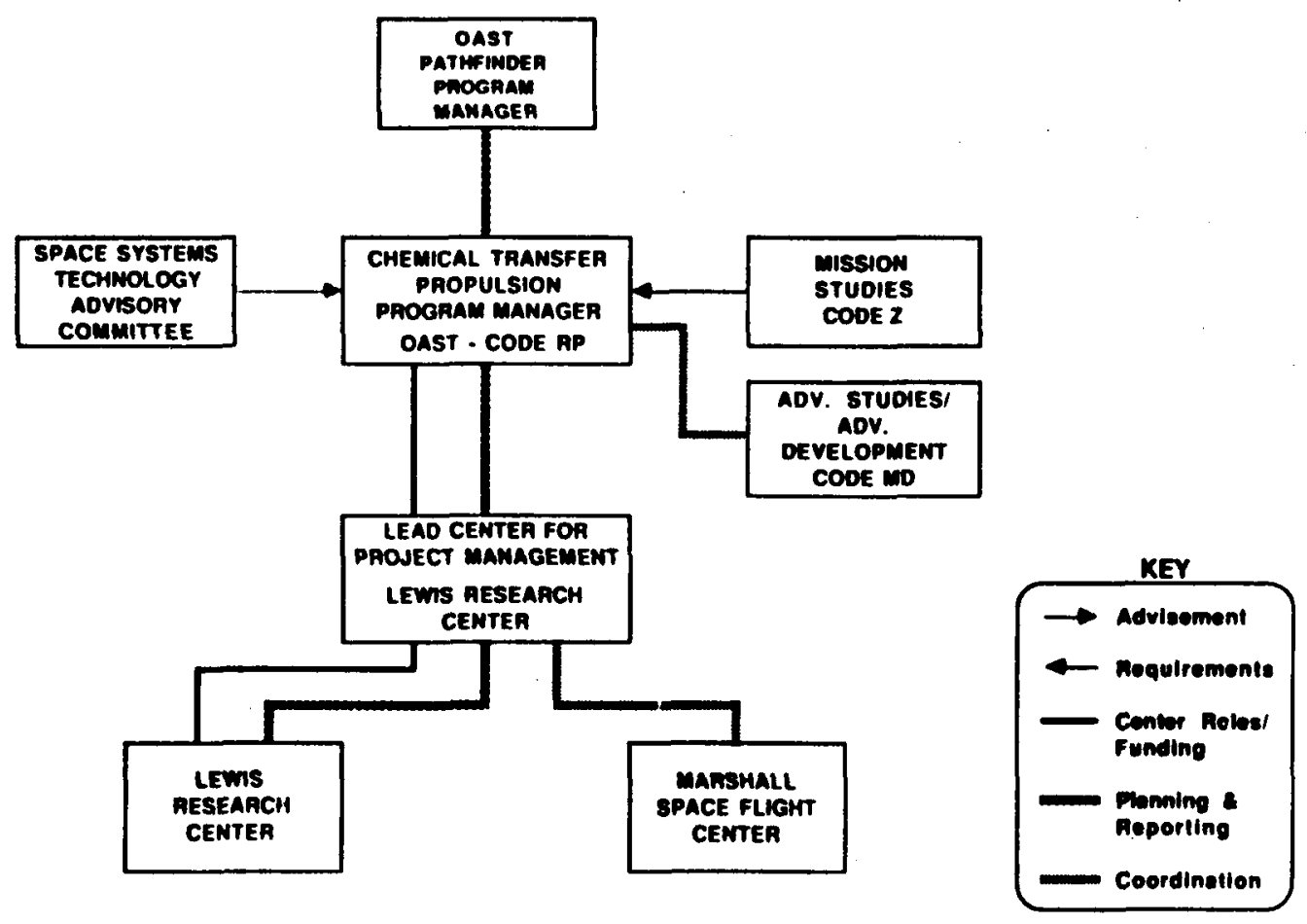

Figure 5: Chemical Transfer Propulsion Management Structure 


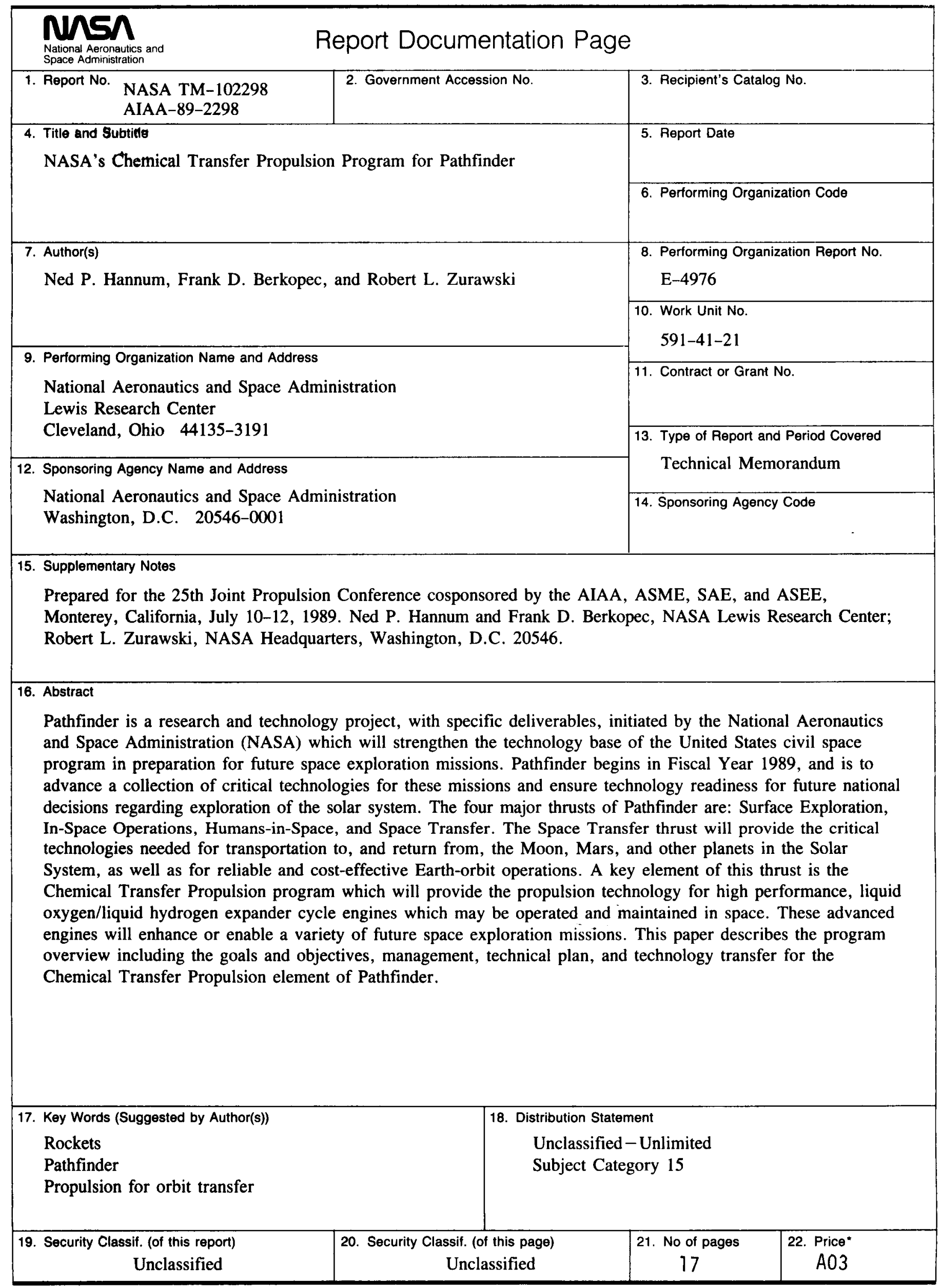

